\title{
Therapeutic itinerary: trajectory for resolution of adverse events of patients using warfarin in Southern Brazil
}

\author{
Christiane Colet $^{1 *}$, Tânia Alves Amador², Isabela Heineck²
}

\begin{abstract}
${ }^{1}$ Departamento de Ciências da Vida, Universidade Regional do Noroeste do Estado do Rio Grande do Sul, Ijuí, Rio Grande do Sul, Brasil ${ }^{2}$ Faculdade de Farmácia, Universidade Federal do Rio Grande do Sul, Porto Alegre, Rio Grande do Sul, Brasil
\end{abstract}

\begin{abstract}
Warfarin is the most used anticoagulant in primary health care. Due to the narrow therapeutic index, its users are more susceptible to adverse events. The objective of this study was to describe the itinerary of the public health sector patients for resolution of adverse events related to warfarin. It is a prospective open cohort, held for a period of 18 months with warfarin users of the Brazilian public health system. Data were collected by monthly interviews and from patient records. Results: Sixty nine patients were interviewed, 64 of them completed monitoring and five died. Bleeding and venous thromboembolism were more frequent in patients starting treatment. It was observed that when adverse events have occurred, in most cases the patient held self-care at home (57\%). During the follow-up, five patients were hospitalized for bleeding. Approximately half of the patients did not present their INR exams to the doctor. Conclusions: This study demonstrates weaknesses in caring for these patients and the need to accompany them, aiming to standardize and guide the itinerary of the anticoagulated patient to solve their problems and improve safety in drug treatment, with less cost to the public health system.
\end{abstract}

Keywords: Warfarin/adverse drug. Cohort studies. Health services accessibility. Reaction. Brazil.

\section{INTRODUCTION}

Therapeutic itineraries are conceptualized as the route taken by individuals or groups, in order to preserve or restore health, and can be used for different features, ranging from home care and religious practices to the primary health care, health care emergencies, among others (Cabral, 2011).

According to Oliveira and colleagues (2014) studies on users's itineraries in search of health care can significantly contribute to the understanding of the behavior during treatment, as well as the use of health services, representing an important tool for the improvement of health assistance. Studies on therapeutic itineraries are relatively recent in Brazil (Cabral, 2011) and have been more frequent in developing countries (Diop et al., 2014), where there is greater concern about rationalizing health care.

The study of therapeutic itineraries can be applied

\footnotetext{
*Correspondence: C. Colet. Departamento de Ciências da Vida, Universidade Federal do Rio Grande do Sul. Rua do Comércio, 3000 - Bairro Universitário, Ijuí, Rio Grande do Sul-RS, Brasil. E-mail: chriscolet@yahoo.com.br
}

for different diseases (Pereira et al., 2014; Silva et al., 2012; Soares, Santos, Arruda, 2017) and for the use of drugs (Bueno, Guerin, Rossoni, 2014), like warfarin. This medication is associated with the risk of adverse events, due to its narrow therapeutic index, variable dose-response and numerous drug interactions (Ansell et al., 2005). Adverse events arising from interactions range from small bleeds to severe bleeding, requiring hospitalizations (Simon et al., 2016). The incidence of bleeding ranges from 4.6 to 15.4 reactions/100 patients/year, whereas embolic events range from 0.75 to 2.57 reactions/ 100 patients/year (Cressman et al., 2015; Labaf et al., 2014; Benhamou et al., 2009; Pastori et al., 2015).

Warfarin is the oral anticoagulant of choice in the Brazilian public health system (Brazil, 2017). One of the determining factors for its election is the low cost in relation to drugs recently introduced in the market (Silva, 2012).

Because of the adverse events, warfarin is associated with hospital admissions and increased search for health services (Howard et al., 2007) showing the importance of exploring the therapeutic itinerary of patients using this drug. 
It is essential to know how these users access the health service for the resolution of adverse events in the different levels of care. This knowledge can support actions for care reorganization and raising new studies and insights on the subject. Thus, the aim of this study is to describe the therapeutic itinerary of patients in the public health sector for the resolution of adverse events related to warfarin.

\section{METHODS}

\section{Study design}

Data were obtained through a prospective open cohort, which included individuals using warfarin linked to the network of public health system of Ijuí, south of Brazil.

Municipal Pharmaceutical Services offers 15 places where drugs are dispensed linked to Basic Health Units (BHU). Dispensing is performed by pharmacy attendants/trainees, without supervision of a pharmacist. The municipality does not have computerized system for dispensing drugs, then the prescription copy, stored in the Central Pharmacy of the Municipal Secretariat of Health (SMS), was accessed for information.

All prescriptions which contained warfarin were selected. Later, it was identified among the network drug dispensing units, the one where the user takes his/ her drugs. With this information, patients' charts were accessed, allowing the identification of the residential address, telephone data, and so, the scheduling of home visits. With this information, patients' charts were accessed, allowing the identification of the residential address, telephone data, and so, the scheduling of home visits.

The identification of the participants took place in February 2014. The follow up of patients was done for a maximum period of 18 months and a minimum of 12 months, between April 2014 and October 2015. In the first six months (until October 2014) there was recruitment of new patients starting warfarin use.

Were included all patients using warfarin orally, for chronic treatment, living in the city of Ijuí/RS, which were outcome-free at baseline. Moreover, they would had to withdrew their medicines in the public health system, and sign the Terms of Consent. In the first home visit, patients were excluded if: reported being from other municipalities, had exchanged anticoagulant or had purchased their drugs in private services. In case of bedridden patients with speech difficulties, interviews were carried out with the caregiver or guardian.

\section{Data collection and study procedures}

Data collection was performed using an instrument previously tested and developed specially for this research. The questionnaire investigates aspects related to the patient (socioeconomic and demographic characteristics), to the use and prescription of warfarin (duration of use, dose, schedule of administration, prescriber specialty, information provided by the doctor about this medication and regular medical consultation), and to the search for medical care (access to health services, considering: BHU, Emergency Room/Emergency and Hospital and reason to search). Monthly, patients were asked whether they had presented any adverse event, such as bleeding and thromboembolism, and also what kind of health care they had used in these situation (home care and/or health services listed above).

Health problems and adverse events were referred by the patients in the first interview and monitored during monthly visits. Adverse events were also obtained by selfreport, confirmed later with access to medical records, when the patient sought medical or hospital care.

In $3^{\text {rd }}, 10^{\text {th }}$ and $18^{\text {th }}$ months, blood samples were taken and the INR (International Normalized Ratio) was evaluated. The test results were delivered to users and, in the subsequent interview, users were asked whether they had shown the tests to the doctor.

Data analysis

The therapeutic routes carried out by patients were classified as: a) self-care at home; b) Basic Health Units; c) Emergency and d) Hospitalization.

Data were analyzed by SPSS software 18 version and presented as frequencies, measures of central tendency and dispersion of the sample (SPSS, 2009).

\section{Ethical aspects}

All study participants signed the Terms of Consent. The project was approved by the Committee of Ethics in Research of the Federal University of Rio Grande do Sul, under identification No. 336.259/2013.

\section{RESULTS}

Of 98 patients with prescription of warfarin, 69 users were located and interviewed. The flow chart 1 presents details about losses and refusals. Most of the patients were of the female gender, with an average age of $64.3 \pm 13.7$. Data are presented in Table I.

For data analysis, the patients were divided into beginners $(n=17 / 25 \%)$ and in use of warfarin for 
TABLE I - Socioeconomic characteristics of users of the public health service of Ijuí, in use of warfarin. Ijuí/RS $n=69^{*}$

\begin{tabular}{lcc}
\hline & F & \% \\
\hline Gender & & \\
$\quad$ Feminine & 38 & 55.1 \\
$\quad$ Masculine & 31 & 45.6 \\
Age & & \\
$\quad 30-49$ & 11 & 15.9 \\
$50-59$ & 12 & 17.4 \\
$60-69$ & 19 & 27.5 \\
$70-79$ & 19 & 27.5 \\
$80-89$ & 6 & 8.7 \\
$90-99$ & 2 & 2.9 \\
Education & & \\
Incomplete Elementary School & 43 & 62.3 \\
Complete Elementary School & 5 & 7.2 \\
Complete High School & 11 & 15.9 \\
Complete Higher Education & 10 & 14.5 \\
Income & & \\
1 SM & 36 & 52.2 \\
2 SM & 20 & 28.9 \\
3 SM & 7 & 10.2 \\
$>3$ SM & 6 & 8.7 \\
\hline * Respons obtained in the first mon
\end{tabular}

${ }^{*}$ Responses obtained in the first month of patients follow-up

more than one year $(\mathrm{n}=51 / 75 \%)$ (Figure 1). During the study period, 88 events of bleeding and 5 events of thromboembolism were observed. These events were more frequent among beginner patients, with 31 cases of bleeding and 5 of thromboembolism. Furthermore, all patients who died (four by thromboembolism and one by bleeding) were patients with more than one year of warfarin use, elderly, polymedicated and presenting comorbidities.

Figure 1 and 2 show the itinerary data of patients to the resolution of the adverse events described above. It was observed that $12.9 \%$ sought at first care in Basic Health Units. Among those who have opted for self-care at home $(57.0 \%), 16(26.2 \%)$ reported that they held local asepsis and bandage; one of them (1.6\%) was concerned in monitoring the situation and other one $(1.6 \%)$ suspended the use of warfarin. It was found that most of them opted for self-care at home, reporting already taken this conduct in previous events or the difficulty of access to health services. It was noticed that part of the patients did not understand the gravity of the situation and the need to get help.
Also, Figure 2 shows that five (7.3\%) patients were hospitalized for bleeding or thrombosis, 7 (10.3\%) initially sought the emergency service and after were hospitalized. In some cases, patients adopted self-care as first care, but after it was necessary to seek for Health Unit (9.7\%) and/or Emergency Service (7.6\%) to resolve the problem.

Most patients $(91.0 \%)$ reported that warfarin was prescribed by an expert, however, subsequent prescriptions and dosage adjustments are usually made by doctors that work at Basic Health Units. Among the patients who reported medical consultations in the follow-up period (68.1\%), most (47.0\%) had one to three appointments..

Regarding the fact of showing the results of INR tests to the doctor, this procedure was adopted by $52.2 \%$ of patients after the first examination, $57.9 \%$ after the second examination and $40.6 \%$ after the third examination. The dose of warfarin has changed in $46.2 \%$ of cases in which patients have shown the test results to the doctor. Table II shows the number of INR tests performed per year. Most patients $(73.5 \%)$ held from one to five INR tests, including the three of them carried out by the research.

There were shortages of warfarin in public municipal health system between the months 13 and 16. It was found that $24.9 \%$ to $43.5 \%$ of patients, depending on the month, did not acquire the medicine for this lack.

\section{DISCUSSION}

One of the results observed in this study was the high incidence of adverse events, as bleeding, thromboembolism and death. Gado and colleagues (2015) highlight that adverse effects of medicines are related to: lack of knowledge of the patient about his illness and medication; forgetfulness; social and economic factors, and adherence.

It can be seen that new warfarin users experienced more bleeding events and venous thromboembolism. According to the literature, the greatest risk of bleeding among users of warfarin occurs within the first 30 days of therapy (Kelling et al., 2011). It was observed that beginners seek more medical service as a result of adverse events than patients with more time of use. However, the number of regular consultations was not higher in this group. In this period, a greater number of dose adjustments are necessary, and it is the moment in which the patient needs greater attention on the part of the health care team.

It was found that the deaths occurred by bleeding or thromboembolism in patients treated with warfarin for one year or more. All had aggravating factors that should have been considered. The data of hemorrhagic events range from 4.6 to 15.4 events/100 patients/year and embolic 


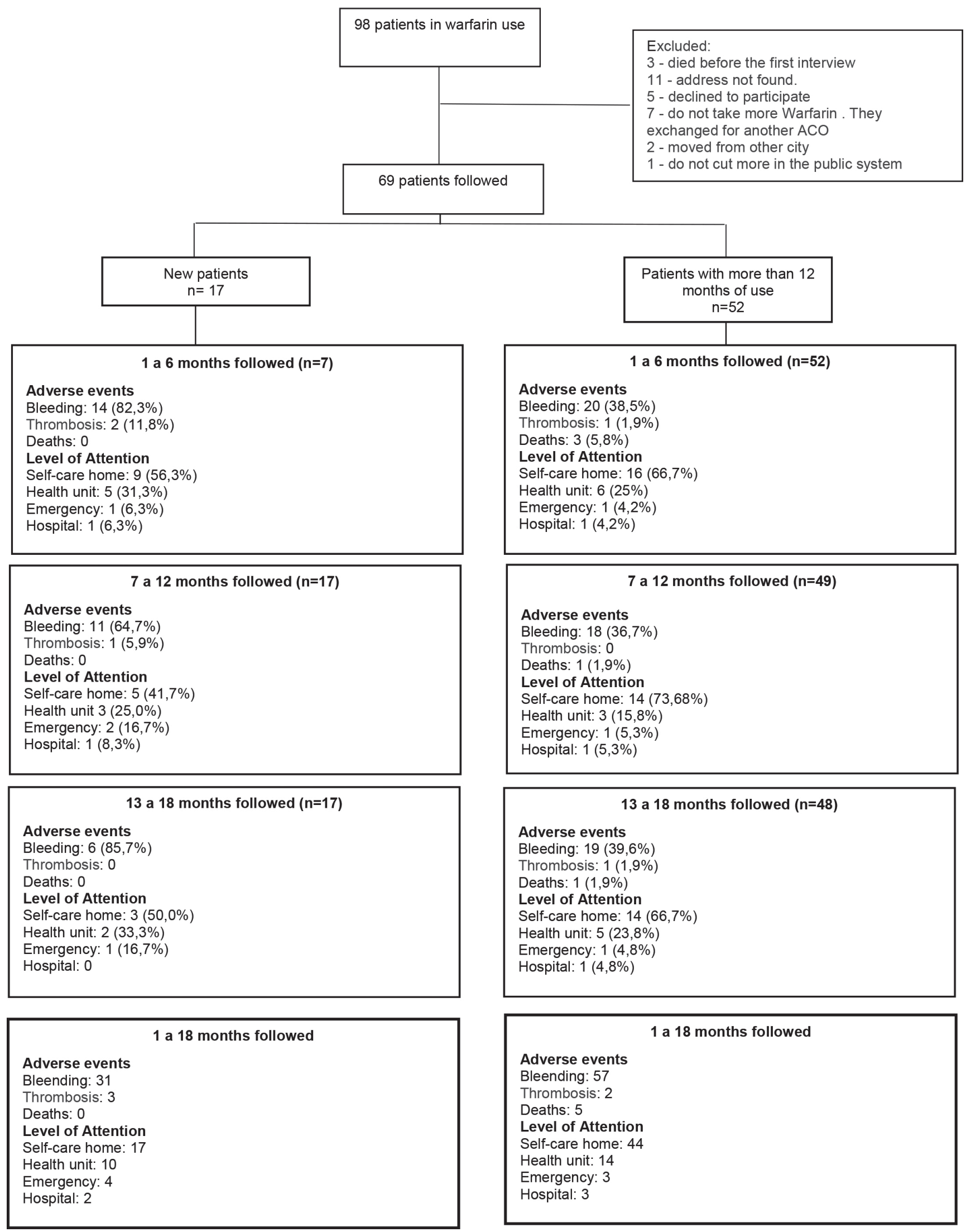

FIGURE 1 - Itinerary of patients for the resolution of adverse events, according to the warfarin use of time and level of attention to every six months in cohort monitoring in the city of Ijuí/RS. $n=69$ 


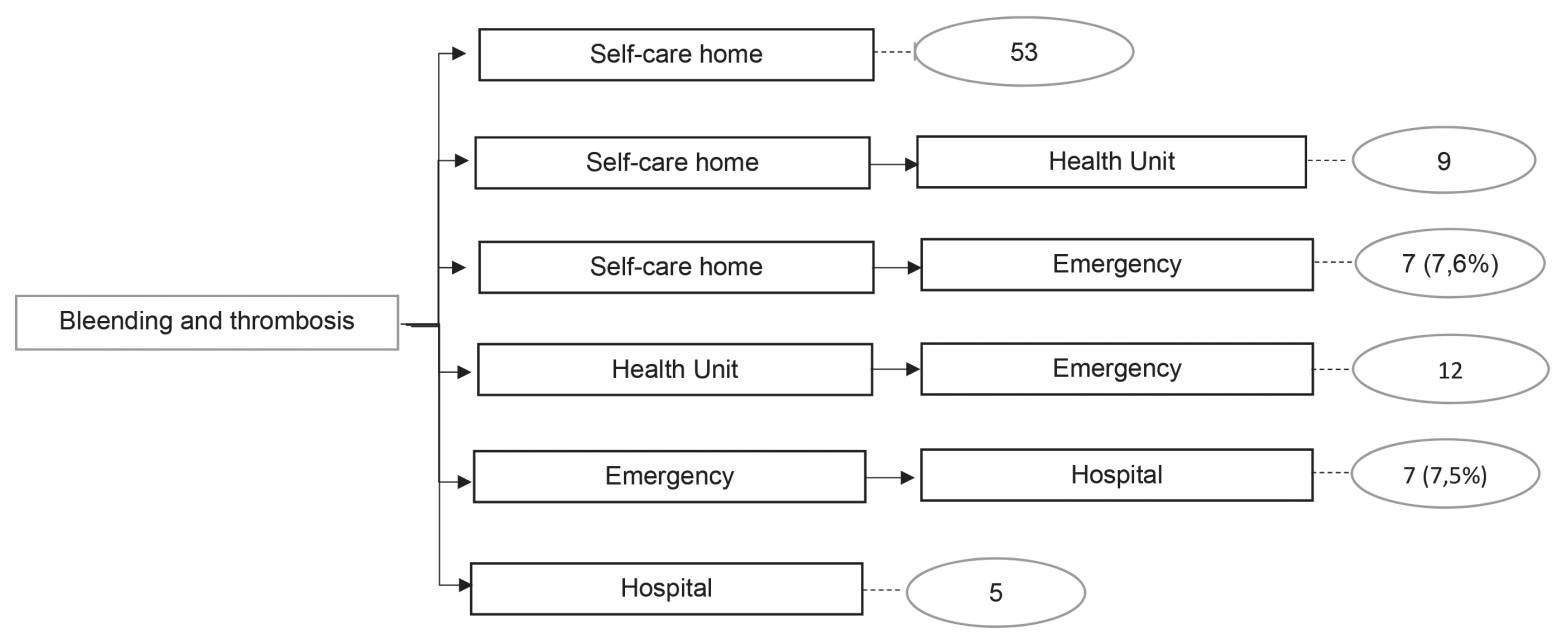

FIGURE 2. Itinerary of patients for the resolution of bleending and thrombosis, according to the warfarin considering the level of attention in cohort monitoring in the city of Ijuí/RS. $n=69$

TABLE II - Frequency of examination and conduct in relation to the result of the INR, in the municipality cohort of Ijuí/RS n= 69

\begin{tabular}{cc}
\hline & $\mathbf{n}(\mathbf{\%})$ \\
\hline Number of INR tests/year $^{*}$ & \\
\hline $1-5$ & $50(72.4)$ \\
$6-10$ & $16(23.2)$ \\
$>10$ & $3(4.4)$ \\
\hline
\end{tabular}

Conduct adopted by the patient in relation to the result of the examination

\begin{tabular}{lc}
\hline Took the exam to the doctor & $104(50.2)$ \\
Change the dose & $48(46.2)$ \\
None & $49(47.1)$ \\
Suspension of warfarin & $7(6.7)$ \\
\hline Did not take the exam to the doctor & $103(49.8)$ \\
None & $78(75.7)$ \\
Changed the dose on his/her own & $20(19.4)$ \\
Suspended the medicine on his/her own & $5(4.9)$ \\
\hline
\end{tabular}

Note: $*=18$ months of follow-up

event contents ranged from 0.75 to 2.57 events $/ 100$ patients/year (Labaf et al., 2014; Pastori et al., 2015). These data demonstrate the need for greater monitoring of this drug, considering it's chronic use and that the adverse events could be avoided.

When the patients in this study were affected by adverse events, the most adopted conduct was home selfcare, indicating that part of the respondents usually take care of their health first on their own, using the informal health system. The fact that patients try to delay search for help in the Health Units has been pointed out by anotheres studies (Dræbel, Gueth, 2014; Ouendo et al., 2005;
Schoze, Silva, 2005). However, the severity of events can be a determining factor to define the therapeutic itinerary. It should be noted, in this regard, the need to establish lines of care for anticoagulated patients in the municipality, through the elaboration of municipal protocols, in order to create a network of assistance in cases of adverse events and seeking a constant and continuous monitoring to prevent these events.

The highest percentage observed for the conduct of home self-care may be related to the severity of the events, but also indicates the need for improvement in education actions for the patients to have more autonomy and control their treatment, that has proved effective for anticoagulated patients(Ouendo et al., 2005).

The difficulty in accessing to health services was one of the reasons why some patients opted for home selfcare for bleeding. The study of Schoze and Silva (2005) showed that the greatest difficulty of the respondents referred to the opening hours of the Health Center and the difficulty in scheduling appointments. In the present research, the Health Units work only during business hours, which may hinder the access to those patients who work during the day. Another factor is the limited daily medical consultations, which can also become a barrier to the anticoagulated patient presenting adverse events.

The difficulty to access the health system may result in a worsening of the clinical picture. This statement can be confirmed in the present study, as among the patients hospitalized for bleeding, seven of them sought first the Health Unit. The events were not identified and treated appropriately, generating the need for hospitalization. For Dubeux, Freese, Felisberto (2013) the main problems identified by users of the health system in research on the itinerary were: the professional did not resolve the health 
problem $(59.0 \%)$, the hospital was far away from home $(58.5 \%)$ and delay to the service (58.5\%). Oliveira et al. (2014) points out that from the illness to the realization of the correct diagnosis and early specific treatment, patients end up walking a long way, not rarely resulting in hospitalization, which would be a flag of the failures of care that, if well managed, could stop or prevent this trajectory.

The need for hospitalization, pointed out in this study as result of bleeding also shows problems in solving the primary care. Primary health care has important role to prevent the illness, expand coverage, ensuring access of the population to services, providing resolute outpatient care, in order to avoid hospitalization and deleterious consequences (Oliveira et al., 2014) In this way, is a challenge to professionals and managers to guarantee the access and turn the health services resolute (Novaczyk, Gaiva, 2010; Hayakawa et al., 2010; Guerin, Rossoni, Bueno, 2012).

Research shows that the late forwarding to the specialist and to the start of treatment may be a factor responsible for emergency hospitalizations (Araújo et $a l ., 2014)$. In the present study, the initial requirements of the anticoagulant were performed by specialists, but the following care was done by doctors that work at Basic Health Units. These doctors, in some cases, may not have a better understanding about anticoagulation and about monitoring the anticoagulated patient. This may influence treatment adherence and the resolution of adverse events. The low number of exams to monitor the INR can indicate problems in monitoring. Moreover, a study conducted in anticoagulation outpatient service shows lower incidence of adverse events than in this study (Orensky, Holdford, 2005).

Other result that needs to be discussed is the conduct of some of the patients that do not take their INR examinations to the doctor. This data can show lack of commitment of the patients with their treatment, but in particular can be a result of ignorance of its importance and the difficulty of access to health services. The specialized clinics for treatment of anticoagulated patients already demonstrated its importance for INR maintenance in the therapeutic range, when compared with care provided only by family doctor (Bungard et al., 2013). Deen (2011) describes the reduction of risks related to the use of ACO in patients monitored on an anticoagulation outpatient service.

In anticoagulation outpatient services patients are assisted by a multidisciplinary team. The interdisciplinary approach is essential for therapeutic success because the establishment of individualized objectives for patients with multiple comorbidities and/or complicated social situations (Perone et al., 2012). However, the fragmented view of the various professionals prevails, originating inadequate referrals and screening (Visentin, Lenardt, 2010).

The resoluteness in primary care is linked to the instrumental resource and technical knowledge of professionals, and also to the link established with the user. (Schoze, Silva, 2005). In this way, the concern about how people look for help to resolve their demands or health problems have been increasingly present in studies on planning, organization and evaluation of health assistance services, since the user's itinerary in the search for therapeutic care does not necessarily coincide with paths predetermined by the health system (Cabral et al., 2011).

It is noteworthy that this study is subject to inherent biases in observational studies. Limitations of the study were that information collected was self-reported by the patients, some patients were not located due to address registration problems. In addition, the drug interactions were not considered and bleeding was not classified according to severity.

In conclusion, it was observed that patients try to delay going to the Health Units with the use of self-care to resolve adverse events of warfarin. This attitude, in some cases, worsens the clinical picture, requiring more complex services like emergency or hospitalization.

\section{REFERENCES}

Ansell J, Hirsh J, Poller L, Bussey H, Jacobson A, Hylek E. The pharmacology and management of the vitamin $\mathrm{K}$ antagonists: the Seventh ACCP Conference on Antithrombotic and Thrombolytic Therapy Chest. 2005;127(1):415-6.

Araújo RCS, Silva RAR, Bezerra MX, Onofre MS, Araújo AEV, Silva KMP. Itinerário terapêutico de pacientes renais crônicos em tratamento dialítico. J Res Fundam Care Online. 2014;6(2):525-38.

Benhamou Y, Cam-Duchez VL, Schneller J-M, Cailleux $\mathrm{N}$, Magne J-C, Soubrane J-C, et al. Expérience d'un centre de suivi et de conseil des traitements anticoagulants oraux en médecine de ville: résultats à cinq ans: Anticoagulation clinics for outpatients: A 5-year experience. Rev Méd Interne. 2009;30(7):567-572.

Brazil. Ministério da Saúde. Secretaria de Ciência, Tecnologia e Insumos Estratégicos. Departamento de Assistência Farmacêutica e Insumos Estratégicos. Relação Nacional de Medicamentos Essenciais: RENAME 2017. Brasília: Ministério da Saúde, 2017. 210 p. 
Bueno D, Guerin GD, Rossoni E. Itinerário terapêutico de usuários de medicamentos de uma Unidade de Estratégia de Saúde da Família. Rev APS. 2014;17(1):50-7.

Bungard TJ, Barra AR, Jones C, Brocklebank C. Pharmacotherapy. Patient satisfaction with services provided by multidisciplinary anticoagulation clinics. Pharmacoth. 2013;33(11):1246-51.

Cabral ALL, Martinez-Hemáez A, Andrade EIG, Cherchiglia ML. Itinerários terapêuticos: o estado da arte da produção científica no Brasil. Cien Saude Colet. 2011;16(11):4433-42.

Cressman AM, Macdonald EM, Yao Z, Austin PC, Gomes T, MHS, et al. Socioeconomic status and risk of hemorrhage during warfarin therapy for atrial fibrillation: A population-based study. Am Heart J. 2015;170(1):133-140.

Deen RJ. Use of direct observed therapy to confirm compliance in a warfarin clinic. Patient Saf. 2011;7(4):232-3.

Diop DSSA, Attinsounon CA, Deguenonvo LF, Diallo VMP, Seydil M. Therapeutic itinerary of severe malaria in adults admitted to a teaching hospital in Dakar, Senegal. J Infect Dev Ctries. 2014;8(10):1353-5.

Dræbel T, Gueth KB. Lay perceptions of malaria and therapeutic itinerary of resettled pregnant women in South Sudan. Int Health. 2014;6(4):317-21.

Dubeux LS, Freese E, Felisberto E. Access to regional emergency hospitals: approach to users to assess itinerary and obstacles to health services. Physis Rev Saúde Colet. 2013;23(2):345-69.

Gadó K, Kocsis E, Zelkó R, Hankó B, Kovácsné Balogh J, Forczig M, et al. Drug compliance of patients on anticoagulant treatment. Orv Hetil. 2015;156(32):1281-7.

Guerin GD, Rossoni E, Bueno D. Itinerários terapêuticos de usuários de medicamentos de uma unidade de Estratégia de Saúde da Família. Cien Saude Colet. 2012;17(11):3003-10.

Hayakawa LY, Marcon SS, Higarashi IH, Waidman MAP. Rede social de apoio a família de crianças internadas em uma unidade de terapia intensiva pediátrica. Rev Bras Enferm. 2010;63(3):440-5.

Howard RL, Avery AL, Slavenburg S, Royal S, Pipe G, Lucassen P, et al. Wich drug 2007;63(2):136-47.
Kelling D, Bagling T, Tait C, Watson H, Perry D, Baglin C, et al. Guidelines on oral anticoagulation with warfarin -4 th edition. Brit J Haematol. 2011;154(3):311-24.

Labaf A, Grzmala-Lubanski B, Stagmo M, Lovdahl S, Sjalander S, Svensson PJ. Thromboembolism, major bleeding and mortality in patients with mechanical heart valves- a populationbased cohort study. Thrombosis Res. 2014;134(2):354-9.

Novaczyk AB, Gaiva MAM. As tecnologias inter-relacionais na assistência a criança na atenção básica: análise de documentos oficiais. Cien Cuid Saude. 2010;9(3):560-8.

Oliveira K, Veronez MI, Marques CDC, Higarashi IH, Marcon SS. Itinerário percorrido pelas famílias de crianças internadas em um hospital escola. Rev Bras Enferm. 2014;67(1):36-42.

Orensky IA, Holdford DA. Predictors of noncompliance with warfarin therapy in an outpatient anticoagulation clinic. Pharmacoth. 2005;25(12):1801-8.

Ouendo EM, Makoutode M, Paraiso MN, Dramaix MW, Dujardin B. Itineraire therapeutique des malades indigents au Benin (Pauvrete' et soins de sante). Trop Med Int Health. 2005;10(2):179-86.

Pastori D, Pignatelli P, Saliola M, Carnevale R, Vicario T, Del Ben $\mathrm{M}$, et al. Inadequate anticoagulation by vitamin $\mathrm{K}$ antagonista is associated with major adverse cardiovascular events in patientes with atrial fibrilation. Int J Cardiol. 2015;15(201):513-6.

Pereira MO, Sa MC, Miranda L. Um olhar sobre a atenção psicossocial a adolescentes em crise a partir de seus itinerários terapêuticos. Cad. Saúde Pública. 2014;30(10):2145-54.

Perone N, Schusselé Filliettaz S, Haller DM, Schaller P, Raetzo MA, Garin N, et al. Clinical itinerary for heart failure: a program designed by primary care practitioners in Geneva. Rev Med Suisse. 2012;8(341):1056-60.

Proietti M, Lip GY. Major outcomes in atrial fibrillation patients with one risk factor: impact of time in therapeutic range observations from the SPORTIF trials. Am J Med. 2016;24(16):352-7.

Schoze AS, Silva YF. Riscos potenciais à saúde em itinerário de cura e cuidado. Rev Cogitare Enferm. 2005;10(2):9-16. 
Silva NEK, Sancho LG, Figueiredo WS. Entre fluxos e projetos terapêuticos: revisitando as noções de linha do cuidado em saúde e itinerários terapêuticos. Ciênc Saúde Colet. 2016;21(3):84351.

Silva P. Velhos e novos anticoagulantes orais. Perspectiva farmacológica. Rev Port Cardiol. 2012;31(Suppl 1):6-16.

Simon TA, Pan X, Kawabata H, Huang HY, Azoulay L. The association between bleeding and the incidence of warfarin discontinuation in patients with atrial fibrillation. Cardiovasc Ther. 2016;34(2):94-9.
Soares DA, Santos EM, Arruda IS. Itinerário terapêutico de pessoas com câncer: produção cientifica no Brasil. Rev APS. 2017;20(1):118 -29.

SPSS Inc. Released 2009. PASW Statistics for Windows, Version 18.0. Chicago: SPSS Inc.; 2009.

Visentin A, Lenardt MH. O itinerário terapêutico: história oral de idosos com câncer. Acta Paul Enferm. 2010;23(4):486-92.

Received for publication on $13^{\text {th }}$ November 2017 Accepted for publication on $12^{\text {th }}$ January 2018 